\title{
Vulvovaginal-gingival Syndrome: As a Rare Variant of Erosive Lichen Planus
}

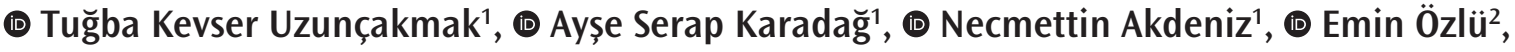 \\ (1) Ebru Itır Zemheri
}

${ }^{1}$ Istanbul Medeniyet University, Goztepe Training and Research Hospital, Clinic of Dermatology, Istanbul, Turkey

2Duzce University Faculty of Medicine, Department of Dermatology, Duzce, Turkey

3Umraniye Training and Research Hospital, Clinic of Pathology, Istanbul, Turkey

\section{ABSTRACT}

Observation: The Vulvovaginal-Gingival syndrome is an uncommon variant of erosive mucosal lichen planus (LP) which is characterized by erosions and desquamation of the vulva, vagina, and gingiva that may lead to mucocutaneous scarring and vaginal stricture formation in long time. Due to its progression the early diagnosis and treatment through a multidisciplinary approach is essential. Treatment is usually difficult and unforunately there are no evidence based studies in the treatment. Herein we want to present a 63-year-old female with a 10 year history of erosions over oral and genital region which was consistent with erosive LP histologically. Topical clobetasole propionate cream and systemic acitretin $25 \mathrm{mg} / \mathrm{d}$ were administered for her initial therapy but on the sixth month of this therapy minimal regression was detected and we have changed this therapy with systemic corticosteroids. Clinical symptoms were regressed almost $50 \%$ on 2 nd month of this therapy. We want to present this case to remind this unusual and treatment resistant form of LP in differential diagnoses of erosive lesions of mucosal surfaces.

Keywords: Acitretin, Lichen planus, Vulvovaginal-Gingival syndrome

\section{Introduction}

Lichen planus (LP) is a chronic immune mediated inflammatory disorder with unknown etiology, effecting both skin and mucosal surfaces [1]. Mucosal involvement is usually characterized by oral mucosal lesions and involvement of other mucosal surfaces such of vulvovaginal region is rare and may also be challenging in differential diagnoses. The prescence of erosive LP of the vulva and vagina with desquamative gingivitis has been described as Vulvovaginal-Gingival syndrome or Hewitt-Pelisse syndrome and there are only a few case reports regarding this rare and severe syndrome in the literature [2,3].

\section{Case Report}

A 63-year-old female presented to our outpatient clinic with a 10 year history of erosions over oral and genital mucosa. Dermatological examination revealed widespread hyperemia and erosions on gingival surfaces, buccal mucosa and marked atrophy and erythema on bilateral labium minus (Figure 1, 2). We performed two punch biopsies and a direct immunflourescence investigation from genital mucosa with initial diagnoses of LP, lichen sclerosus and pemfigus vulgaris. Histopathological examination revealed widespread band like lichenoid infiltration (Figure 3) and direct immunflorescence was negative. She was diagnosed as Vulvovaginal-Gingival syndrome and topical clobetasole propionate cream and systemic acitretin 25

Address for Correspondence: Tuğba Kevser Uzunçakmak MD, Istanbul Medeniyet University, Goztepe Training and Research Hospital, Clinic of Dermatology, Istanbul, Turkey

Phone: +90 5306640226 E-mail: drtugbakevser@gmail.com 0RCID ID: orcid.org/0000-0001-8057-3463

Received: 06.02.2020 Accepted: 10.02.2020

${ }^{(C)}$ Copyright 2020 by the Society of Academy of Cosmetology and Dermatology / Journal of the Turkish Academy of Dermatology published by Galenos Publishing House. 


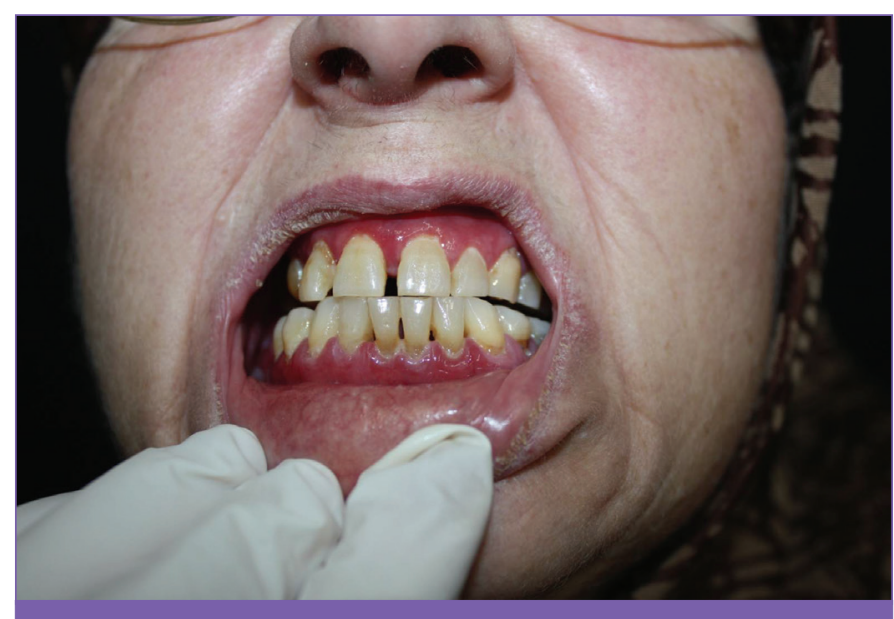

Figure 1. Widespread hyperemia and erosions on gingival surfaces

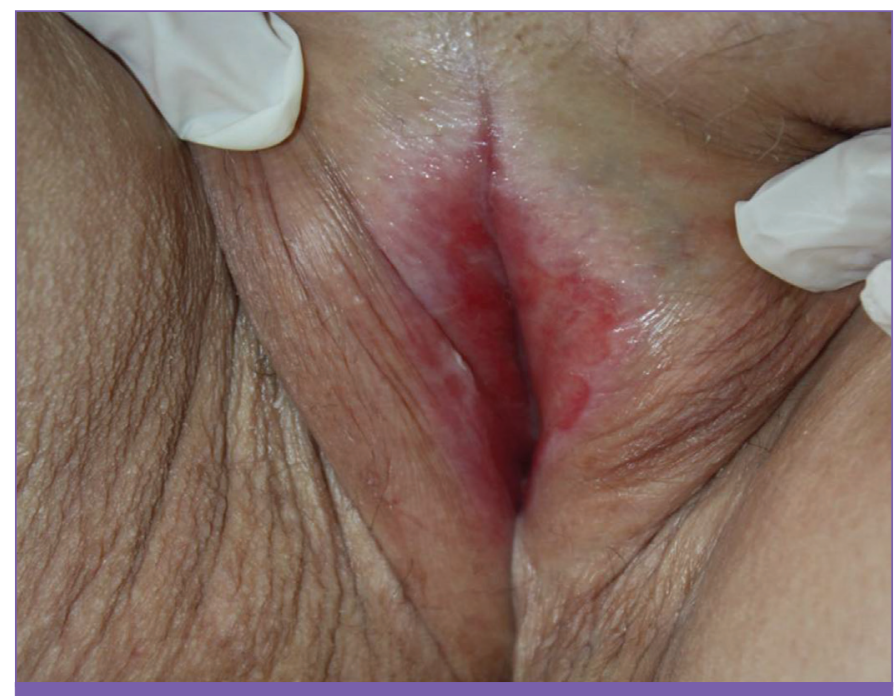

Figure 2. Marked atrophy and erythema on bilateral labium minus

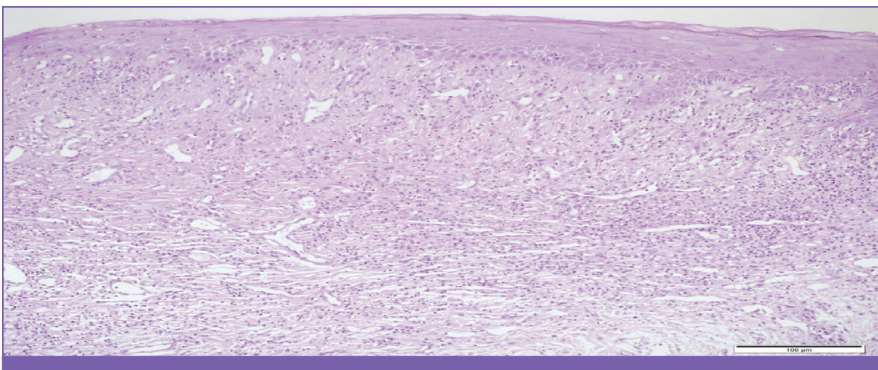

Figure 3. Microscopically, hyperkeratosis, achantosis and focal basal vacuoler changes in epidermis, vascular proliferation, band-like infiltration of lymphocytes in dermis were seen. This findings are compatible to late period of lichen planus

$\mathrm{mg} / \mathrm{d}$ were administered. On sixth month of this therapy minimal regression was detected and she was still suffering from itching and pain on genital region so we have changed this therapy with systemic corticosteroids. Systemic methylprednisolone $60 \mathrm{mg} / \mathrm{d}$ was administered and was given with $20 \%$ of tapering doses biweekly. Clinical symptoms were regressed almost $50 \%$ on $2^{\text {nd }}$ month of this therapy. After cession of the prednisolone on $6^{\text {th }}$ month her lesions reactivated and systemic cyclosporine $200 \mathrm{mg} / \mathrm{d}$ was initiated, marked remission was detected on her genital lesions. She is still under follow up with systemic cyclosporine and topical clobetasol propionate cream.

\section{Discussion}

LP is an idiopathic, inflammatory, immune mediated disorder which may affect both mucosal surfaces, such as the oral, genital mucosa, and the skin including the scalp and nails [4]. Ocular, esophageal, bladder, nasal, laryngeal, otic, gastric, and anal involvement have been also reported in the literature but the most common mucosal involvement is seeen in oral mucosa [4]. Oral mucosal lesions are generally characterized by whitish-gray reticular or annular patches or strings that may be present mostly $(80 \%)$ in the buccal mucosa, followed by tongue, lips, in floor of mouth and palate [5]. Vesicle and bullae formation may be also seen [5]. In recent studies the role of overexpression of tumor necrosis factor-alpha in the cytoplasm of basal epithelial keratinocytes was shown in etiopathogenesis of erosive LP which may be target in the treatment [6].

Different than classical cutaneous involvement of LP, mucosal lesions may progress to sequelae formation leading to mucosal stenosis which really impacts on regional functions such as opening of the mouth, dysurea, dysparonia, postcoital bleeding and increased risk of malignant change in long time duration.

Vulvovaginal-Gingival syndrome was first described in 1982 by Pelisse et al. as a special form of erosive mucosal LP and up to date there are very few case reports about this syndrome in the literature. It is challenging if this variant of LP is likely to be underreported or really a rare disorder. Most of the patients have been usually treated as vaginal yeast infections or other diagnosis such as idiopathic desquamative vaginitis, idiopathic erosive vulvitis and vulvar lichen sclerosus [7]. We performed histological examination and direct immunflorescence with these differential diagnoses and it was consistent with erosive LP. Recognition of Vulvovaginal-Gingival syndrome may avoid unnecessary medical and surgical procedures and also may prevent patients from malignant progression.

Early diagnosis and treatment is very important to prevent the patients from genital sequelae formation. Topical corticosteroids are usually the first step of treatment and they are also the most commonly used drugs. Topical tacrolimus may also be topical treatment option. Systemic agents include corticosteroids, azathioprine, acitretin, metronidazole, mycophenolate mofetil and adalimumab [8]. In our patient we initiated systemic acitretin 
because of her age and her diabetes history but in $6^{\text {th }}$ month of there were no satisfactory results and we offered systemic corticosteroids for faster recovery with close monitorization of blood sugar. Almost $50 \%$ remission was detected on second month of this therapy without any recurrence but six months after the treatment cession her lesions reactivated. We couldn't start systemic corticosteroids because of her disregulated blood sugar and age. We have initiated systemic cyclosporine for her lesions and again achieved a marked remission in her lesions.

We want to present this case to remind this unusual form of mucosal LP in differential diagnoses of erosive lesions of mucosal surfaces especially anogenital region and gingival surfaces. We also want to lay emphasis on examination of all mucosal surfaces in patients who presented with oral mucosal erosions.

\section{Ethics}

Informed Consent: Patient consent was taken before therapy and photographs.

Peer-review: Internally peer-reviewed.

\section{Authorship Contributions}

Surgical and Medical Practices: T.K.U., A.S.K., E.I.Z., Concept: T.K.U., E.Ö., Design: T.K.U., A.S.K., E.Ö., Data Collection or Processing: T.K.U., E.Ö., E.I.Z., Analysis or Interpretation: T.K.U., A.S.K., N.A., E.I.Z., Literature Search: T.K.U., N.A., Writing: T.K.U.
Conflict of Interest: No conflict of interest was declared by the authors.

Financial Disclosure: The authors declared that this study received no financial support.

\section{References}

1. Krupaa RJ, Sankari SL, Masthan KM, Rajesh E. Oral lichen planus: An overview. J Pharm Bioallied Sci 2015;7(Suppl 1):S158-161.

2. Gökdemir G, Baksu A, Tașkin M, Göker N. Vulvovaginal-gingival syndrome of lichen planus: diagnostic and therapeutic challenge. Aust N Z J Obstet Gynaecol 2003;43:389-390.

3. Buffon RB, Lisboa AP, Carvalho F, Muller KR, Bonamigo RR. Vulvovaginalgingival lichen planus--a rare or underreported syndrome? Int J Dermatol 2009; 48:322-324.

4. Rogers RS, Eisen D. Erosive oral lichen planus with genital lesions: the vulvovaginal-gingival syndrome and the peno-gingivalsyndrome. Dermatol Clin 2003;21:91-98.

5. Krupaa RJ, Sankari SL, Masthan KM, Rajesh E. Oral lichen planus: An overview. J Pharm Bioallied Sci 2015;7(Suppl 1):S158-161.

6. Ho JK, Hantash BM. Treatment of recalcitrant vulvovaginal gingival syndrome with adalimumab. J Am Acad Dermatol 2011;65:e55-57.

7. Wu Y, Qiao J, Fang H. Syndrome in question. An Bras Dermatol 2014;89:843844 .

8. Büyük AY, Kavala M. Oral metronidazole treatment of lichen planus. J Am Acad Dermatol 2000;43:260-262. 